\title{
Transcatheter valve-in-valve implantation for degenerated stentless aortic bioroots
}

\author{
Davut Cekmecelioglu $^{1,2}$, Ourania Preventza ${ }^{1,2}$, Kathryn G. Dougherty ${ }^{2}$, Subhasis Chatterjee ${ }^{1,2,3}$, \\ Susan Y. Green ${ }^{1,4}$, Guilherme V. Silva ${ }^{5}$, Jose G. Díez ${ }^{5,6}$, Joseph S. Coselli ${ }^{1,2}$ \\ ${ }^{1}$ Division of Cardiothoracic Surgery, Michael E. DeBakey Department of Surgery, Baylor College of Medicine, Houston, Texas, USA; ${ }^{2}$ Section of \\ Adult Cardiac Surgery, Department of Cardiovascular Surgery, Texas Heart Institute and CHI St Luke's Health—Baylor St Luke's Medical Center, \\ Houston, Texas, USA; ${ }^{3}$ Division of General Surgery, Michael E. DeBakey Department of Surgery, Baylor College Medicine, Houston, Texas, USA; \\ ${ }^{4}$ Office of Surgical Research, Michael E. DeBakey Department of Surgery, Baylor College of Medicine, Houston, Texas, USA; ${ }^{5}$ Section of Cardiology, \\ Department of Medicine, Baylor College of Medicine, Houston, Texas, USA; ${ }^{6}$ Department of Cardiology, Texas Heart Institute, Houston Texas, \\ USA \\ Correspondence to: Ourania Preventza, MD. Division of Cardiothoracic Surgery, Michael E. DeBakey Department of Surgery, Baylor College of \\ Medicine, BCM 390, One Baylor Plaza, Houston, TX 77030, USA. Email: preventz@bcm.edu.
}

Background: Open surgical repair of a failed valve-sparing aortic root replacement (VSARR) or stentless bioroot aortic root replacement (bio-ARR) entails significant operative risks. Whether valve-in-valve transcatheter aortic valve replacement (ViV-TAVR) is feasible in patients with a previous VSARR or stentless bio-ARR remains unclear, given lingering concerns about the ill-defined aortic annulus in these patients and the potential for coronary obstruction. We present our experience with patients who had a previous VSARR or stentless bio-ARR and underwent ViV-TAVR to repair a degenerated aortic valve with combined valvular disease, aortic insufficiency and aortic stenosis.

Methods: In this retrospective data review, we identified and analyzed consecutive patients with a previous VSARR or stentless bio-ARR who underwent ViV-TAVR between December 1, 2014 and August 31, 2019.

Results: ViV-TAVR was performed in twelve high-risk patients with previous VSARR or bio-ARR during the study period. Of these, seven received Medtronic Freestyle porcine stentless bioprosthetic aortic roots, three received homograft aortic roots, one underwent a Ross procedure and one underwent VSARR. ViVTAVR restored satisfactory valve function in all patients, and technical success was $100 \%$. No patient had more than mild regurgitation after implantation. No thirty-day mortality was seen. One patient had major bleeding after transapical access, one patient had a transient ischemic stroke, and one patient needed permanent pacemaker implantation. At a median last follow-up of 21.5 months (interquartile range, 9.0-69.0 months), all patients remained alive and had satisfactory valve function.

Conclusions: In this study, ViV-TAVR was a clinically effective option for treating patients with a failed stentless bio-ARR or previous VSARR. Short-term and intermediate-term results after these procedures were favorable. These findings may have important implications for treating high-risk patients with structural aortic root deterioration and call for better transcatheter heart valves that are suitable for treating aortic insufficiency.

Keywords: Stentless aortic valve; stentless aortic root; aortic root replacement (ARR); transcatheter aortic valve replacement (TAVR); valve-in-valve $(\mathrm{ViV})$

Submitted Jul 10, 2021. Accepted for publication Jul 29, 2021.

doi: 10.21037/acs-2021-tviv-124

View this article at: https://dx.doi.org/10.21037/acs-2021-tviv-124

(C) Annals of Cardiothoracic Surgery. All rights reserved. Ann Cardiothorac Surg 2021;10(5):641-650 I https://dx.doi.org/10.21037/acs-2021-tviv-124 


\section{Introduction}

Stentless bioprosthetic aortic valves and aortic valve-sparing procedures are associated with excellent hemodynamics, infrequent patient-prosthesis mismatch and avoidance of lifelong anticoagulation therapy $(1,2)$. They have been used in young patients with aortic root aneurysms, adults with aortic root aneurysms for whom anticoagulation is contraindicated, patients with genetic tissue disorders, and patients with native or prosthetic aortic root endocarditis (3-11). Bioprosthetic valves have limited durability, and most require reintervention within 7 to 15 years (2,12-14). Conversely, the durability of VSARR, although excellent when performed by experienced surgeons (5), remains unclear when the procedure is done by less-experienced practitioners.

Stentless root repair (VSARR or Ross procedure) and stentless bioroot replacement (i.e., homograft or porcine bioprosthetic aortic root replacement) are typically accomplished by using modified subcoronary or rootreplacement techniques (Figure 1). Reoperation for previous homograft or stentless bioprosthetic valve failure often demands patch repair of the aortic root, redo total aortic root replacement, graft reconstruction of the left ventricular outflow tract or complex reattachment of previously reimplanted coronary arteries (i.e., the Cabrol technique using interpositioned graft between the replaced aortic root and coronary arteries) $(11,15)$. Moreover, homografts and porcine bioroots can become calcified over time, adding extensive aortic root reconstruction to the reoperative risks associated with surgical aortic valve replacement. We consider these procedures to be among the most difficult operations a cardiac surgeon will perform.

Although current guidelines (16) recommend surgical aortic valve replacement for treating bioprosthesis dysfunction, the associated risk for mortality and periprocedural complications is high $(15,17)$. Conversely, catheter-based treatment for valve dysfunction or bioprosthetic leaflet degeneration may be reasonable for selected patients treated at comprehensive valve centers. The increased complexity, morbidity and mortality associated with reoperation make valve-invalve $(\mathrm{ViV})$ transcatheter aortic valve replacement (TAVR) particularly attractive for inoperable or high-risk patients with degenerated bioprostheses $(2,18-20)$. Nonetheless, using ViV-TAVR to repair degenerated stentless roots and bioroots presents several technical challenges, particularly the absence of radiopaque landmarks from a stent or sewing ring, an ill-defined aortic annulus, operator-specific variations in implantation technique, lack of calcium in the aortic annulus (infrequent) or excessive calcium in the entire aortic root and annulus and proximity of the coronary ostia.

In this study, we reviewed procedural and clinical outcomes of ViV-TAVR used to treat patients with a failed valve-sparing aortic root replacement (VSARR) or stentless bioroot aortic root replacement (bio-ARR) in which the failure was limited to dysfunction of an aortic valve (aortic insufficiency or stenosis) residing within a functional aorticroot complex.

\section{Methods}

Our institutional percutaneous valve database was searched to identify and analyze consecutive patients with a previous VSARR or stentless bio-ARR who underwent ViVTAVR to treat structural aortic valve dysfunction between December 1, 2014 and August 31, 2019. These patients were considered to be at high or extreme high risk for open surgery. The Baylor College of Medicine Institutional Review Board approved the study. Written informed consent was obtained from all participants, and data were collected in accordance with Institutional Review Board policy.

The primary endpoint was all-cause mortality at 1 year. Secondary endpoints included procedural success, stroke, vascular complications, valve embolization and migration, valve hemodynamics, permanent pacemaker implantation and hospitalization rates. Procedural success was defined as successful vascular access; appropriate delivery, deployment and positioning of the transcatheter heart valve (THV); suitable performance of the THV (i.e., mean aortic valve gradient $<20 \mathrm{mmHg}$ or peak velocity $<3 \mathrm{~m} / \mathrm{s}$; aortic valve area $>1.2 \mathrm{~cm}^{2}$ without moderate or severe prosthetic aortic valve regurgitation); and absence of periprocedural death, stroke or myocardial infarction. The Valve Academic Research Consortium 2 (VARC-2) criteria (21) were used to define vascular complications, myocardial infarction, arrhythmia, cerebrovascular events and death.

\section{Preoperative planning}

Patient risk for open surgery was evaluated by a heart-valve team consisting of cardiothoracic surgeons, interventional cardiologists, anesthesiologists and nurse coordinators. The appraisal was based on Society of Thoracic Surgeons Predicted Operative Mortality (STS-PROM) scores and functional status.

The electronic medical record, angiograms, and 


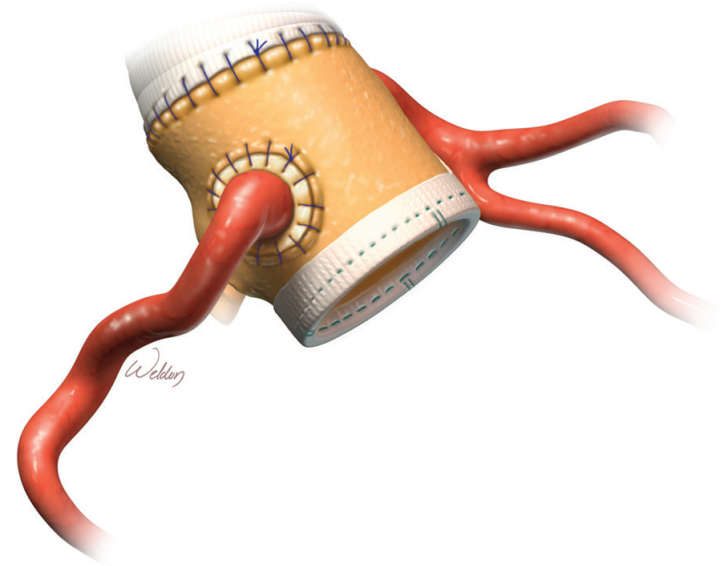

Figure 1 Illustration of aortic root replacement with Medtronic Freestyle porcine stentless bioprosthesis. Printed with permission from Baylor College of Medicine.

echocardiograms were reviewed to capture patient history, previous surgical notes, procedural details, complications, clinical outcomes, and hemodynamic outcomes. For patients with a previous stentless bio-ARR, device details (including manufacturer, model and size) were explicitly obtained, with particular attention given to the coronary artery reimplantation technique. Precise sizing was determined from previous surgical reports and confirmed by examining cardiac computed tomography (CT) images.

We followed our institution's standard workup protocol for ViV-TAVR candidates. Multislice CT imaging provides a detailed, precise description of the root anatomy and geometry, calcium distribution and annular dimension. Peripheral vascular access options were analyzed.

\section{Procedural technique}

Procedures were performed in a hybrid operating room under general anesthesia. Standard ViV-TAVR with either a self-expandable CoreValve Evolut R THV (Medtronic, Minneapolis, MN, USA) or a balloon-expandable Edwards SAPIEN 3 or XT THV (Edwards Lifesciences, Irvine, CA, USA) was performed. The access route was either transfemoral or transapical. The choice of a self-expandable versus a balloon-expandable THV depends on the anatomy and the distance of the previous stentless annulus from the left and right implanted coronaries. Due to various factors (learning curve, ill-defined annulus, or close proximity of the annulus from the implanted coronaries), we prefer to use self-expandable THVs whenever feasible (Figure 2).
We use balloon-expandable THVs in cases that require a transapical approach.

A Perclose ProGlide device (Abbott Vascular, Santa Clara, CA, USA) was used to close the common femoral artery over a J-wire before a large sheath (14 or 18 French) was introduced. A preliminary angiogram of the aortic valve and root was obtained to inform leaflet and cusp alignment and to evaluate anatomy and regurgitation. Fluoroscopic images coaxial to valvular calcifications, or root angiography with a pigtail catheter in the noncoronary sinus in the absence of calcifications was used to help delineate the target landing zone.

The valve was crossed by using a straight-tip 0.035 Amplatz Super Stiff guidewire (Boston Scientific, Marlborough, MA, USA) to advance the catheter. After crossing the aortic valve, the catheter was advanced to the apex of the left ventricle and an exchange wire was placed to insert a pigtail catheter. Balloon predilatation was deliberately avoided to circumvent free aortic regurgitation with hemodynamic compromise during ViV-TAVR. The THV was advanced and positioned at the level of the surgical stentless bioprosthetic valve or at the previous VSARR. A second pigtail was positioned at the noncoronary cusp by the contralateral access used for angiographic guidance. We relied on preoperative angiograms and 3-dimensional cardiac CT images, along with intraoperative 3-dimensional transesophageal echocardiography (TEE), whenever anatomical landmarks were not clear (Figure 2).

The THV was then deployed according to manufacturer instructions. During deployment, we typically use fast ventricular pacing (140-180 beats/minute) to reduce cardiac output, and angiography to ensure precise device alignment. Hemodynamic and imaging evaluations with fluoroscopy and intraprocedural TEE were performed to confirm proper THV deployment. After successful deployment (Figure 3) was confirmed, the ViV-TAVR sheath was removed and sutures from the placed percutaneous closure devices were tightened.

Postprocedural complications and valve hemodynamics were tracked with repeat echocardiograms, clinic visits and phone calls. Follow-ups were planned at discharge, at 30 days, and at 12-month intervals thereafter.

\section{Statistical analysis}

Normally distributed continuous variables are presented as mean $\pm \mathrm{SD}$, non-normally distributed continuous variables are presented as median [interquartile range (IQR)] and 


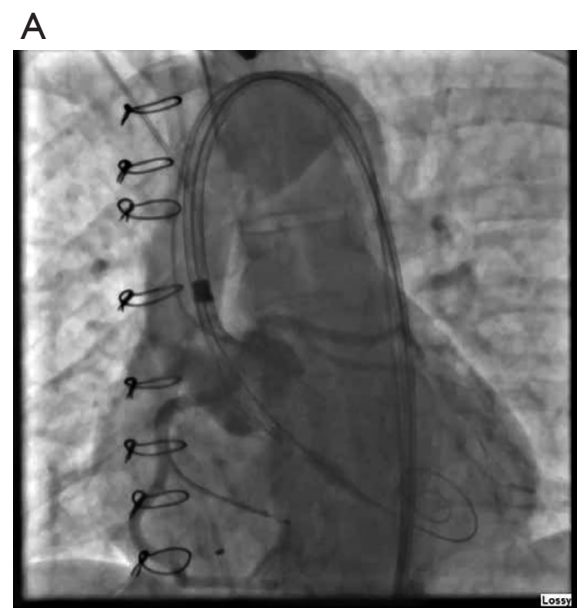

B

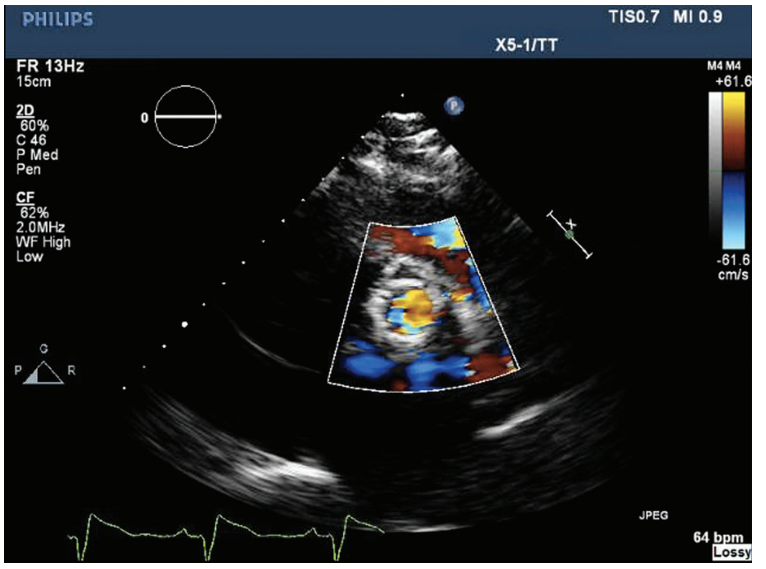

Figure 2 Intraoperative images from a patient who had stentless bioprosthetic aortic root replacement for a degenerated aortic valve. Angiography to enable accurate assessment of the height of the coronary ostia before deployment (A) and transesophageal echocardiography to ensure proper anchoring of the TAVR (B) are crucial. TAVR, transcatheter aortic valve replacement.

A

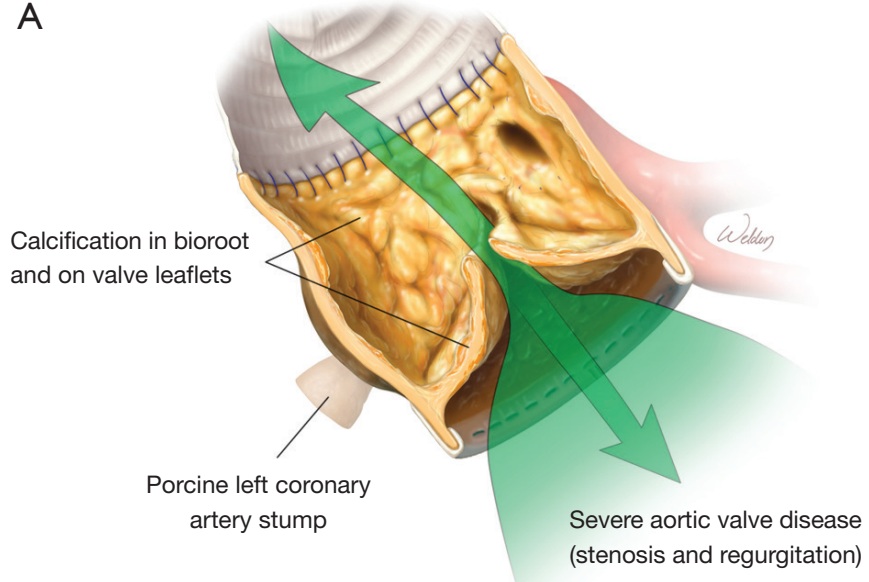

B

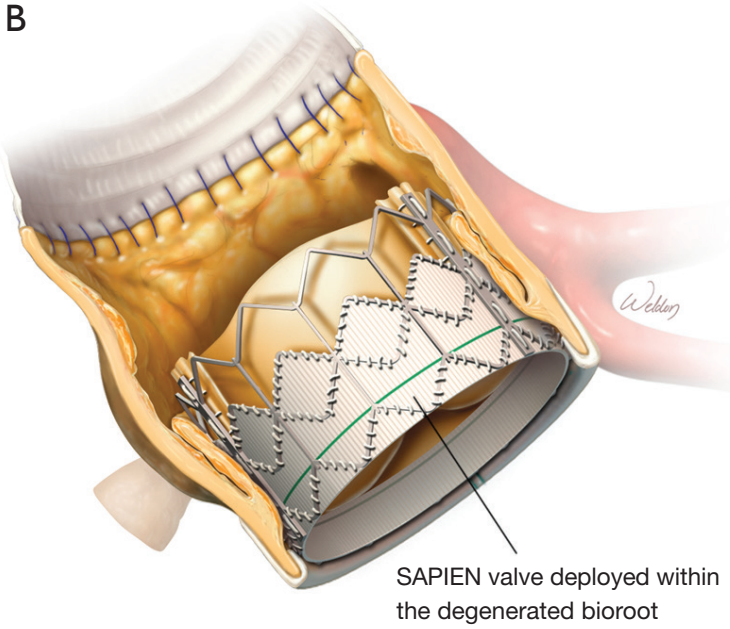

Figure 3 Illustrations of a degenerated stentless bioroot with presentation of severe aortic stenosis and regurgitation (A) and a deployed balloon-expandable transcatheter aortic valve (B). Printed with permission from Baylor College of Medicine.

nominal variables are presented as number (percentage). Continuous variables were compared before and after ViVTAVR by using paired Student $t$-tests. Statistical analyses were performed by using SPSS v.20.0 for Windows (IBM, Chicago, IL, USA).

\section{Results}

\section{Baseline characteristics}

Twelve patients with a degenerated aortic valve from a previous VSARR or stentless bio-ARR underwent elective ViV-TAVR during the study period. Baseline patient demographics are outlined in Table 1. All procedures were performed by the same heart team.

Patients were $54.5 \pm 15.6$ years of age, and most $(75.0 \%)$ were male. The mean STS-PROM score was $9.2 \% \pm 2.2 \%$. Of the 12 study participants, seven had previously received a Freestyle porcine aortic root bioprosthesis (Medtronic) to replace the aortic root, three had undergone homograft aortic root replacement, one had undergone a Ross 


\begin{tabular}{|c|c|}
\hline Characteristic & Value \\
\hline Age (years) & $54.5 \pm 15.6$ \\
\hline Sex (male), n (\%) & $9(75.0)$ \\
\hline Body surface area $\left(\mathrm{m}^{2}\right)$ & $2.0 \pm 0.2$ \\
\hline STS-PROM score (\%) & $9.2 \pm 2.2$ \\
\hline Preoperative LVEF (\%) & $56.5 \pm 6.3$ \\
\hline Hypertension, n (\%) & $6(50.0)$ \\
\hline Diabetes mellitus, n (\%) & $3(25.0)$ \\
\hline Chronic obstructive pulmonary disease, n (\%) & $4(33.3)$ \\
\hline \multicolumn{2}{|l|}{ Coronary artery disease, $\mathrm{n}(\%)$} \\
\hline Previous myocardial infarction & $4(33.3)$ \\
\hline Previous coronary artery bypass grafting & $1(8.3)$ \\
\hline \multicolumn{2}{|l|}{ Preoperative NYHA class, n (\%) } \\
\hline III & $11(91.7)$ \\
\hline IV & $1(8.3)$ \\
\hline \multicolumn{2}{|l|}{ Previous aortic root replacement procedure, n (\%) } \\
\hline Homograft & $3(25.0)$ \\
\hline Porcine bioprosthesis (freestyle) & $7(58.3)$ \\
\hline Ross procedure & $1(8.3)$ \\
\hline VSARR (David I) & $1(8.3)$ \\
\hline \multicolumn{2}{|l|}{ Valvular pathology, $\mathrm{n}(\%)$} \\
\hline Aortic stenosis & $3(25.0)$ \\
\hline Aortic regurgitation & $7(58.3)$ \\
\hline Mixed aortic stenosis/aortic regurgitation & $2(16.7)$ \\
\hline Interval between surgery and ViV-TAVR (years) & $12.0 \pm 4.4$ \\
\hline \multicolumn{2}{|c|}{$\begin{array}{l}\text { Data are expressed as mean } \pm \text { standard deviation or } n(\%) \text {. } \\
\text { STS-PROM, Society of Thoracic Surgeons Predicted Risk of } \\
\text { Mortality; LVEF, left ventricular ejection fraction; NYHA, New } \\
\text { York Heart Association; VSARR, valve-sparing aortic root } \\
\text { replacement; ViV-TAVR, valve-in-valve transcatheter aortic valve } \\
\text { replacement. }\end{array}$} \\
\hline
\end{tabular}

procedure to replace the aortic root with a pulmonary valve autograft, and one had a VSARR (Table 1). On average, patients presented $12.0 \pm 4.4$ years after their primary valve operation.

Bioprosthesis mode of failure was regurgitation in seven patients $(58.3 \%)$, stenosis in two $(16.7 \%)$ and combined

\begin{tabular}{|c|c|}
\hline Characteristic & Value \\
\hline Device alignment success, n (\%) & $12(100.0)$ \\
\hline \multicolumn{2}{|l|}{ Transcatheter valve, n (\%) } \\
\hline Self-expanding & $9(75.0)$ \\
\hline Balloon-expanding & $3(25.0)$ \\
\hline \multicolumn{2}{|l|}{ Access site, $\mathrm{n}(\%)$} \\
\hline Transfemoral & $9(75.0)$ \\
\hline Transapical & $3(25.0)$ \\
\hline \multicolumn{2}{|l|}{ Implanted device size, $\mathrm{n}(\%)$} \\
\hline $23 \mathrm{~mm}$ & $1(8.3)$ \\
\hline $26 \mathrm{~mm}$ & 4 (33.3) \\
\hline $29 \mathrm{~mm}$ & $4(33.3)$ \\
\hline $34 \mathrm{~mm}$ & $3(25.0)$ \\
\hline Mean aortic valve gradient $(\mathrm{mmHg})$ & $9.7 \pm 4.8$ \\
\hline \multicolumn{2}{|l|}{ Paravalvular leak, n (\%) } \\
\hline Mild & $4(33.3)$ \\
\hline Moderate & $1(8.3)$ \\
\hline New pacemaker requirement, $\mathrm{n}(\%)$ & $1(8.3)$ \\
\hline Postimplantation dilatation, $\mathrm{n}(\%)$ & $1(8.3)$ \\
\hline Contrast amount (cc) & $145.5 \pm 86.7$ \\
\hline Fluoroscopy time (min) & $17.0(8.3-57.9)$ \\
\hline Hospital stay (days) & $4.0 \pm 2.3$ \\
\hline
\end{tabular}

aortic stenosis and regurgitation in three (25.0\%). All patients had severe symptomatic aortic regurgitation and were New York Heart Association class III or IV.

\section{Procedural characteristics}

Procedural details are summarized in Table 2. The access route was transfemoral in nine patients $(75.0 \%)$ and transapical in three (25.0\%). The self-expandable CoreValve Evolut R THV was used in the nine transfemoral-access cases, whereas balloon-expandable Edwards SAPIEN THVs were used in the three transapical-approach cases. Preimplantation balloon aortic valvuloplasty was not 


\begin{tabular}{lll}
\hline \multicolumn{3}{l}{ Table 3 Major adverse cardiac and cerebrovascular events } \\
\hline Adverse outcome & 30 days & Last follow-up* \\
\hline $\begin{array}{l}\text { Major adverse cardiac and } \\
\text { cerebrovascular events }\end{array}$ & $1(8.3 \%)$ & $1(8.3 \%)$ \\
\hline Death & 0 & 0 \\
\hline Stroke & $1(8.3 \%)$ & $1(8.3 \%)$ \\
\hline Renal failure & 0 & 0 \\
\hline Myocardial infarction & 0 & 0 \\
\hline Major bleeding & $1(8.3 \%)$ & $1(8.3 \%)$ \\
\hline Permanent pacemaker & $1(8.3 \%)$ & $1(8.3 \%)$ \\
\hline
\end{tabular}

Data are expressed as n (\%). *, median 21.5 months (IQR, 9.069.0 months).

performed in any patient.

The average previous stentless aortic valve sizes in the self-expandable and balloon-expandable groups were $24.71 \pm 2.05$ and $24.33 \pm 3.05 \mathrm{~mm}$, respectively. The average THV sizes in these groups were $29.3 \pm 4.0$ and $27.0 \pm 1.7 \mathrm{~mm}$, respectively. Median fluoroscopy time was 17.0 minutes (IQR, 8.3-57.9 minutes), and mean contrast volume used was $145.5 \pm 86.7 \mathrm{cc}$.

\section{Clinical outcomes}

Procedural success was achieved in all patients (100\%). Satisfactory valve function was restored in all patients. Only one patient $(8.3 \%)$ had more than mild aortic regurgitation after implantation; for this patient, the regurgitation was moderate and had improved by the last follow-up. For all patients, no new mitral regurgitation was seen on any intraoperative echocardiogram. No deaths occurred inhospital, within 30 days postoperatively or by the last follow-up [median 21.5 months (IQR, 9.0-69.0 months)]. One patient $(8.3 \%)$ had major bleeding after transapical access that required re-exploration, and one $(8.3 \%)$ had a transient ischemic stroke postoperatively but developed no neurological sequelae (Table 3).

One patient $(8.3 \%)$ needed permanent pacemaker implantation. Coronary ostial obstruction did not occur in any case. There were no vascular complications, per VARC2 criteria.

The mean intensive care unit stay was $1.3 \pm 0.6$ days, and the average hospital stay was $4.0 \pm 2.3$ days. All 12 patients were discharged directly home after ViV-TAVR. All had symptomatic relief, having improved from New York Heart Association class III or IV to class I at discharge. All were independently able to perform daily activities.

\section{Echocardiographic data and outcomes}

At the last follow-up, all patients were alive and had satisfactory valve function. Left ventricular ejection fraction was slightly lower than normal at baseline [60\% (IQR, $45-65 \%)]$ and was clinically no different at the last followup [60\% (IQR, 50-69\%)]. Left ventricular volumes were lower at the last follow-up: End-diastolic volumes were $159 \mathrm{cc}$ (IQR, 125-444 cc) at baseline versus $129.5 \mathrm{cc}$ (IQR, 88-188 cc) at follow-up ( $\mathrm{P}=0.04)$, and end-systolic volumes were $83.5 \mathrm{cc}(\mathrm{IQR}, 36-269 \mathrm{cc}$ ) at baseline versus $74 \mathrm{cc}$ (IQR, $26-103 \mathrm{cc})$ at follow-up $(\mathrm{P}=0.08)$. The aortic valve gradient decreased from $24.0 \mathrm{mmHg}$ (IQR, $10.0-62.0 \mathrm{mmHg}$ ) at baseline to $8.0 \mathrm{mmHg}$ (IQR, $3.0-21.0 \mathrm{mmHg}$ ) at the last follow-up $(\mathrm{P}=0.007)$.

\section{Discussion}

In this study, we investigated clinical results from 12 consecutive patients with a high redo surgical risk profile (evidenced by a mean STS-PROM score of $9.2 \% \pm 2.2 \%$ ) who underwent ViV-TAVR to repair stentless surgical bioroots or previous VSARR. Stentless aortic valves are autografts, heterografts or homografts sutured to the aortic root in the position of a native valve; eliminating the support stent (frame) improves hemodynamic performance and durability $(22,23)$. With time, these valves develop calcification and fibrosis, which can extend from the aortic root into the left ventricular outflow tract and around the coronary ostia. These calcifications may injure the coronary ostia, aortic wall, aortic annulus, anterior mitral valve leaflet or the membranous septum, posing a particular challenge for reoperation. Such risks are not adequately addressed in the STS-PROM risk score (24). The ViV-TAVR procedure is typically reserved for high-risk patients requiring redo surgery and for elderly patients.

In 2007, Wenaweser et al. (25) reported the first case of a Medtronic CoreValve THV implanted into a degenerated surgical aortic bioprosthesis. Since then, numerous reports of ViV-TAVR with either the CoreValve or an Edwards SAPIEN bioprosthesis have been published (26-31). Choi et al. compared surgical ViV in patients with stentless aortic valves $(n=32)$ versus ViV-TAVR in patients with degenerated stented aortic valves $(\mathrm{n}=8)$. The procedural 
success rate in the stentless group was $96.9 \%$, with $6.9 \%$ allcause mortality at 30 days, versus $100 \%$ procedural success and no mortality in the stented group (32). However, data regarding ViV-TAVR to repair failed stentless bio-ARRs or VSARRs are limited. Our study of ViV-TAVR to repair stentless bioroots or previous VSARR resulted in 100\% procedural success and excellent clinical outcomes in all patients.

In the Valve-in-Valve International Data registry, severe preexisting mismatch between the patient and the failed surgical bioprosthesis was independently and strongly associated with increased risk for mortality after ViV-TAVR (33). Likewise, severe patient-prosthesis mismatch predicted adverse outcomes in a recent study of 62,125 patients from the Transcatheter Valve Therapy registry (34). In the PARTNER-2 registry, a key exclusion criterion was having a previously placed bioprosthetic valve with a labeled size $<21 \mathrm{~mm}$ (35). In our study, the smallest previous stentless bioprosthesis was labeled $23 \mathrm{~mm}$. Of note, the labeling of valve sizes may refer to the internal or outer diameter of the valve. Given the variation in valve types and sizing terminology, operators planning ViV-TAVR must familiarize themselves with the structural components and dimensions of the specific bioprosthesis being treated. Obtaining a detailed operative report also is crucial.

Although stentless bioroot replacement can offer excellent hemodynamics, failure can occur a few years after the initial procedure. In a study of 56 patients with failed Medtronic Freestyle bioprostheses, Wai Sang and colleagues (36) reported an $82 \%$ procedural success rate, with six patients requiring two THVs. In our patients, we implanted only one THV per procedure; prosthesis migration was not seen.

ViV-TAVR implantation is particularly challenging in patients with a previous VSARR or stentless bioARR, given the absence of a frame or structural support (i.e., the stent) on which to anchor the THV, as well as the lack of radiopaque markers to help with appropriate positioning. During surgery, we may place a pacing wire around the annulus of the stentless bio-ARR or on the Dacron graft of the VSARR as a marker for future ViVTAVR. Both balloon-expandable and self-expandable THVs can and should be anchored on the noncompliant Dacron sewn to the annulus below the nadir of the stentless valve leaflets. In patients with a stentless valve and aortic regurgitation, describing the proper aortic annulus is difficult. Perioperatively, we use a multimodality imaging evaluation to assist in positioning the THV. We also use multiple pigtail catheters, which are placed in the right and noncoronary cusps to lead the positioning. Positioning is less difficult in patients with calcification-related aortic stenosis as the primary mode of failure and in patients with a calcified stentless bioroot or homograft complex.

Several techniques have been explored to assist with positioning and deploying THVs in failed stentless valves (37). Rapid ventricular pacing during aortic root injection helps opacify the aortic root and coronaries. The relationship between the occasionally calcified strip of Dacron on the Freestyle bioroot, the nadir of the stentless valve cusps and the coronary arteries is identifiable by using both CT and aortic root angiography. Detailed knowledge of the preoperative 3-dimensional cardiac CT also is essential. Given our meticulous preoperative evaluation, we observed no coronary obstruction or related myocardial infarction in our cohort.

Oversizing of the THV is usually recommended to avoid complications of valve migration, embolization and malpositioning (38). Notwithstanding, implanting an oversized valve risks coronary artery obstruction. Of note, all aortic root replacement necessitates reimplantation of coronary arteries, which may result in imperfectly reconstructed anatomy and could create differences in the distance of the left and right coronary ostia from the annulus; any such inconsistencies are probably caused by the previous aortic root replacement.

In regards to technical aspects of the ViV-TAVR procedure, a repositionable self-expanding valve was preferable to a balloon-expanding valve in most patients $(\mathrm{n}=9,75.0 \%)$, as its supra-annular design results in lower gradients and a larger effective orifice area compared with the balloon-expanding valve. Furthermore, it facilitates proper device positioning when fluoroscopic anatomical landmarks are lacking, especially in patients with a homograft. Balloon predilatation can facilitate crossing or positioning during THV implantation; however, as degenerated stentless bioprostheses are often bulky and friable, we did not apply balloon predilatation in any of the patients. Balloon valvuloplasty also is avoided to preclude the creation of free aortic insufficiency with hemodynamic compromise. A learning curve plays a significant role during these challenging procedures.

\section{Limitations}

The study had the limitations of an observational, retrospective, nonblinded review of a small cohort of 
patients, with all the inherent bias and without independent adjudication of adverse events. Nevertheless, ViV-TAVR is becoming more common, and this study adds valuable information on an important subset of high-risk patientsthose with a failed stentless bio-ARR or VSARR due to combined valvular disease. Importantly, THVs were designed to treat aortic valve stenosis, and there is clear need for manufacturers to develop THVs for patients with aortic valve regurgitation. Lastly, our patients might have survived open reoperation to replace the aortic valve; surgical replacement would have also provided an opportunity to replace the dysfunctional aortic valve with a larger valve, which may have produced better clinical outcomes.

\section{Conclusions}

Aortic root replacement necessitates the reimplantation of coronary arteries onto the new root; inevitably, this process creates variation in the anatomical location of the coronary ostia. In cases of previous aortic root replacement in which failure is limited to the stentless bioprosthetic valve contained with the root structure (such as patients with a previous VSARR, homograft, Ross procedure or porcine bioprosthesis), $\mathrm{ViV}$-TAVR can be performed with low risk for complications such as death, stroke and myocardial infarction, resulting in improved hemodynamics, better quality of life, and favorable left ventricular remodeling, despite the presence of the unique technical challenges described above. Detailed preprocedural planning is essential, along with multislice CT scanning, rapid ventricular pacing during deployment, 3-dimensional TEE and operative knowledge of the previous stentless aortic root operation to facilitate deployment accuracy. Complementary knowledge among the entire heart-valve team, especially between cardiac surgeons and cardiologists, is key for successful outcomes in these challenging cases.

Although initial results with ViV-TAVR therapy in this patient group are encouraging, rigorous evaluation and long-term follow-up are needed to further validate this approach.

\section{Acknowledgments}

Jeanie F. Woodruff, BS, ELS, of the Department of Scientific Publications at the Texas Heart Institute, edited the manuscript, Arin C. Jobe contributed to data collection, and
Scott A. Weldon, MA, CMI, FAMI created the illustrations. Funding: None.

\section{Footnote}

Conflicts of Interest: OP participates in clinical trials with and/or consults for Terumo Aortic and W.L. Gore \& Associates. SC has participated in advisory boards for Edwards Lifesciences \& La Jolla Pharmaceutical Corp. JSC participates in clinical studies with and/or consults for Terumo Aortic, Medtronic, W.L. Gore \& Associates, CytoSorbents, and Abbott Laboratories and receives royalties and grant support from Terumo. The other authors have no conflicts of interest to declare.

Open Access Statement: This is an Open Access article distributed in accordance with the Creative Commons Attribution-NonCommercial-NoDerivs 4.0 International License (CC BY-NC-ND 4.0), which permits the noncommercial replication and distribution of the article with the strict proviso that no changes or edits are made and the original work is properly cited (including links to both the formal publication through the relevant DOI and the license). See: https://creativecommons.org/licenses/by-nc-nd/4.0/.

\section{References}

1. Brown JM, O'Brien SM, Wu C, et al. Isolated aortic valve replacement in North America comprising 108,687 patients in 10 years: changes in risks, valve types, and outcomes in the Society of Thoracic Surgeons National Database. J Thorac Cardiovasc Surg 2009;137:82-90.

2. Dvir D, Webb J, Brecker S, et al. Transcatheter aortic valve replacement for degenerative bioprosthetic surgical valves: results from the global valve-in-valve registry. Circulation 2012;126:2335-44.

3. Coselli JS, Hughes MS, Green SY, et al. Valve-sparing aortic root replacement: early and midterm outcomes in 83 patients. Ann Thorac Surg 2014;97:1267-73; discussion 1273-4.

4. Coselli JS, Weldon SA, Preventza O, et al. Valvesparing versus composite root replacement procedures in patients with Marfan syndrome. Ann Cardiothorac Surg 2017;6:692-6.

5. David TE. Aortic valve sparing operations: outcomes at 20 years. Ann Cardiothorac Surg 2013;2:24-9.

6. Flynn CD, Tian DH, Wilson-Smith A, et al. Systematic 
review and meta-analysis of surgical outcomes in Marfan patients undergoing aortic root surgery by composite-valve graft or valve sparing root replacement. Ann Cardiothorac Surg 2017;6:570-81.

7. LeMaire SA, Green SY, Sharma K, et al. Aortic root replacement with stentless porcine xenografts: early and late outcomes in 132 patients. Ann Thorac Surg 2009;87:503-12; discussion 512-3.

8. Mazine A, El-Hamamsy I, Verma S, et al. Ross Procedure in Adults for Cardiologists and Cardiac Surgeons: JACC State-of-the-Art Review. J Am Coll Cardiol 2018;72:2761-77.

9. Ouzounian M, Feindel CM, Manlhiot C, et al. Valvesparing root replacement in patients with bicuspid versus tricuspid aortic valves. J Thorac Cardiovasc Surg 2019;158:1-9.

10. Price J, Magruder JT, Young A, et al. Long-term outcomes of aortic root operations for Marfan syndrome: A comparison of Bentall versus aortic valve-sparing procedures. J Thorac Cardiovasc Surg 2016;151:330-6.

11. Preventza O, Mohamed AS, Cooley DA, et al. Homograft use in reoperative aortic root and proximal aortic surgery for endocarditis: A 12-year experience in high-risk patients. J Thorac Cardiovasc Surg 2014;148:989-94.

12. Paradis JM, Del Trigo M, Puri R, et al. Transcatheter Valve-in-Valve and Valve-in-Ring for Treating Aortic and Mitral Surgical Prosthetic Dysfunction. J Am Coll Cardiol 2015;66:2019-37.

13. Rodriguez-Gabella T, Voisine P, Puri R, et al. Aortic Bioprosthetic Valve Durability: Incidence, Mechanisms, Predictors, and Management of Surgical and Transcatheter Valve Degeneration. J Am Coll Cardiol 2017;70:1013-28.

14. Coselli JS, Volguina IV, LeMaire SA, et al. Early and 1-year outcomes of aortic root surgery in patients with Marfan syndrome: a prospective, multicenter, comparative study. J Thorac Cardiovasc Surg 2014;147:1758-67.e1-4.

15. Borger MA, Prasongsukarn K, Armstrong S, et al. Stentless aortic valve reoperations: a surgical challenge. Ann Thorac Surg 2007;84:737-43; discussion 743-4.

16. Otto CM, Nishimura RA, Bonow RO, et al. 2020 ACC/ AHA Guideline for the Management of Patients With Valvular Heart Disease: A Report of the American College of Cardiology/American Heart Association Joint Committee on Clinical Practice Guidelines. Circulation 2021;143:e72-e227.

17. Balsam LB, Grossi EA, Greenhouse DG, et al. Reoperative valve surgery in the elderly: predictors of risk and longterm survival. Ann Thorac Surg 2010;90:1195-200; discussion 1201.

18. Bapat V, Davies W, Attia R, et al. Use of balloon expandable transcatheter valves for valve-in-valve implantation in patients with degenerative stentless aortic bioprostheses: Technical considerations and results. J Thorac Cardiovasc Surg 2014;148:917-22; discussion 922-4.

19. Finch J, Roussin I, Pepper J. Failing stentless aortic valves: redo aortic root replacement or valve in a valve? Eur J Cardiothorac Surg 2013;43:495-504.

20. Díez JG, Schechter M, Dougherty KG, et al. Transcatheter Aortic Valve-in-Valve Replacement Instead of a 4th Sternotomy in a 21-Year-Old Woman with Aortic Homograft Failure. Tex Heart Inst J 2016;43:334-7.

21. Kappetein AP, Head SJ, Généreux P, et al. Updated standardized endpoint definitions for transcatheter aortic valve implantation: the Valve Academic Research Consortium-2 consensus document. J Thorac Cardiovasc Surg 2013;145:6-23.

22. Kallikourdis A, Jacob S. Is a stentless aortic valve superior to conventional bioprosthetic valves for aortic valve replacement? Interact Cardiovasc Thorac Surg 2007;6:665-72.

23. Dunning J, Graham RJ, Thambyrajah J, et al. Stentless vs. stented aortic valve bioprostheses: a prospective randomized controlled trial. Eur Heart J 2007;28:2369-74.

24. O'Brien SM, Shahian DM, Filardo G, et al. The Society of Thoracic Surgeons 2008 cardiac surgery risk models: part 2--isolated valve surgery. Ann Thorac Surg 2009;88:S23-42.

25. Wenaweser P, Buellesfeld L, Gerckens U, et al. Percutaneous aortic valve replacement for severe aortic regurgitation in degenerated bioprosthesis: the first valve in valve procedure using the Corevalve Revalving system. Catheter Cardiovasc Interv 2007;70:760-4.

26. Webb JG, Wood DA, Ye J, et al. Transcatheter valve-invalve implantation for failed bioprosthetic heart valves. Circulation 2010;121:1848-57.

27. Piazza N, Bleiziffer S, Brockmann G, et al. Transcatheter aortic valve implantation for failing surgical aortic bioprosthetic valve: from concept to clinical application and evaluation (part 2). JACC Cardiovasc Interv 2011;4:733-42.

28. Ussia GP, Barbanti M, Ramondo A, et al. The valvein-valve technique for treatment of aortic bioprosthesis malposition an analysis of incidence and 1-year clinical outcomes from the italian CoreValve registry. J Am Coll Cardiol 2011;57:1062-8. 
29. Bapat V, Attia R, Redwood S, et al. Use of transcatheter heart valves for a valve-in-valve implantation in patients with degenerated aortic bioprosthesis: technical considerations and results. J Thorac Cardiovasc Surg 2012;144:1372-9; discussion 1379-80.

30. Webb JG, Mack MJ, White JM, et al. Transcatheter Aortic Valve Implantation Within Degenerated Aortic Surgical Bioprostheses: PARTNER 2 Valve-in-Valve Registry. J Am Coll Cardiol 2017;69:2253-62.

31. Duncan A, Davies S, Di Mario C, et al. Valve-in-valve transcatheter aortic valve implantation for failing surgical aortic stentless bioprosthetic valves: A single-center experience. J Thorac Cardiovasc Surg 2015;150:91-8.

32. Choi CH, Cheng V, Malaver D, et al. A comparison of valve-in-valve transcatheter aortic valve replacement in failed stentless versus stented surgical bioprosthetic aortic valves. Catheter Cardiovasc Interv 2019;93:1106-15.

33. Pibarot $P$, Simonato $M$, Barbanti $M$, et al. Impact of Pre-Existing Prosthesis-Patient Mismatch on Survival Following Aortic Valve-in-Valve Procedures. JACC

Cite this article as: Cekmecelioglu D, Preventza O, Dougherty KG, Chatterjee S, Green SY, Silva GV, Díez JG, Coselli JS. Transcatheter valve-in-valve implantation for degenerated stentless aortic bioroots. Ann Cardiothorac Surg 2021;10(5):641-650. doi: 10.21037/acs-2021-tviv-124
Cardiovasc Interv 2018;11:133-41.

34. Herrmann HC, Daneshvar SA, Fonarow GC, et al. Prosthesis-Patient Mismatch in Patients Undergoing Transcatheter Aortic Valve Replacement: From the STS/ ACC TVT Registry. J Am Coll Cardiol 2018;72:2701-11.

35. Webb JG, Murdoch DJ, Alu MC, et al. 3-Year Outcomes After Valve-in-Valve Transcatheter Aortic Valve Replacement for Degenerated Bioprostheses: The PARTNER 2 Registry. J Am Coll Cardiol 2019;73:2647-55.

36. Wai Sang SL, DeBruine N, Beute T, et al. Midterm Outcomes for Valve-in-Valve Transcatheter Aortic Valve Replacement in the Failed Freestyle Bioprosthesis. Ann Thorac Surg 2020;110:1951-7.

37. Dvir D, Leipsic J, Blanke P, et al. Coronary obstruction in transcatheter aortic valve-in-valve implantation: preprocedural evaluation, device selection, protection, and treatment. Circ Cardiovasc Interv 2015;8:e002079.

38. Noorani A, Radia R, Bapat V. Challenges in valve-in-valve therapy. J Thorac Dis 2015;7:1501-8. 